DOI: $10.5007 / 2175-7941.2013 v 30 n 1 p 58$

\title{
CATEGORIZAÇÃO DE QUESTÕES DE FÍSICA DO NOVO ENEM ${ }^{+*}$
}

\author{
Jesusney Silva Hernandes \\ Instituto Federal Goiano \\ Morrinhos - GO \\ Maria Inês Martins \\ Pontifícia Universidade Católica de Minas Gerais \\ Belo Horizonte - MG
}

\begin{abstract}
Resumo
Este artigo estuda questões que envolvem Física nas provas de Ciências da Natureza e suas Tecnologias do novo ENEM. Selecionamos itens que evidenciam alguma Física nessas provas. Classificamos as questões por Competência e Habilidade segundo a matriz de referência do Exame e, através da análise de conteúdo de Bardin (2010), propusemos, para cada grupo de itens inseridos em uma dada competência, um agrupamento em categorias. A partir da observação e reflexão das categorias emergentes, apresentamos, ao longo do texto, orientações sobre características das situações-problema que abordam alguma Física no novo ENEM. Além disso, através da análise das categorias emergentes, procuramos avaliar a aproximação das questões selecionadas com as orientações presentes nos Parâmetros Curriculares Nacionais para o Ensino Médio (PCNEM), nas Orientações Complementares aos Parâmetros Curriculares Nacionais (PCN+) e nas Orientações Curriculares para o Ensino Médio (OCEM). Percebemos que muitas
\end{abstract}

Classification of Physics questions of the new ENEM (National Exam for High School Students in Brazil)

* Recebido: agosto de 2012.

Aceito: fevereiro de 2013. 
orientações que surgiram das categorias emergentes atendem às orientações dos PCN, PCN+ e OCEM. Esperamos que nossa pesquisa possa contribuir para o alinhamento da prática docente com um ensino de Física inovador, pautado no desenvolvimento de competências e habilidades, viabilizando melhoria de aprendizado e, consequentemente, de desempenho em Exames como o ENEM.

Palavras-chave: Análise de Conteúdo. Questões de Física. Novo ENEM.

\begin{abstract}
This article addresses Physics questions in tests of Natural Sciences and their Technologies under the new ENEM. In these tests, we selected items (questions) that highlighted some aspect of Physics. The questions were classified for Competence and Skill according to the test reference matrix, and using Bardin's content analysis (2010), we proposed that each group of items under a given competence is grouped into categories. From the observation and analysis of emerging categories we presented some guidelines on characteristics of problem-solving situations related to Physics in the new ENEM. Besides, through analysis of the emerging categories, we attempted to evaluate the compliance of the selected questions to the guidelines established under the Brazilian National Curriculum Parameters for High School (PCNEM), the Complementary Guidelines to the Brazilian National Curriculum Parameters (PCN+) and the Guidelines to the National Curriculum for High School (OCEM). We realized that many guidelines from the emerging categories are consistent with PCN, PCN+ and OCEM guidelines. We hope that our research will contribute to the alignment of teaching practice by promoting an innovative teaching of Physics focused on the development of competences and skills, aimed to improve learning, thus improving performance in exams such as the ENEM.
\end{abstract}

Keywords: Content analysis. Physics questions. New ENEM. 


\section{Introdução}

O Exame Nacional do Ensino Médio (ENEM) passou por uma modificação em sua estrutura no ano de 2009, quando ampliou a sua utilização como via de acesso ao Ensino Superior. Muitas instituições federais de Ensino Superior (IFES) que não utilizavam a nota do ENEM em seus processos seletivos começaram a usá-la como forma de instrumento parcial ou único de ingresso.

A proposta de utilização do ENEM como método de seleção unificada nos processos seletivos das universidades públicas federais foi apresentada pelo Ministério da Educação (MEC) em 2009, acompanhada de uma proposta de reformulação do exame. Tais medidas foram aceitas por grande parte das IFES e o novo ENEM implantado no mesmo ano. Essa mudança na política de ingresso em cursos superiores, nos mostra que é necessário estar em sintonia com as novas perspectivas do exame reformulado, o que se pretende neste trabalho em relação à Física.

Pesquisas sobre a Física nas provas do ENEM vêm sendo realizadas. Silva e Prestes (2009) estudaram as questões do velho ENEM que contêm Física em sua formulação nas edições de 2006, 2007 e 2008. No trabalho desses autores, a análise das questões do ENEM foi realizada nas dimensões linguístico-cognitiva, científica, tecnológica, social e das interações Ciência, Tecnologia, Sociedade e Ambiente (CTSA). Na dimensão científica, a análise mostrou que as questões de 2006 a 2008 que abordam conhecimentos de Física utilizam principalmente o conceito de energia em suas diversas formas e suas transformações, inclusive abordando fenômenos de interação da radiação eletromagnética com a matéria e aspectos de Física nuclear. Segundo os autores, as questões do ENEM de 2006 a 2008 não cobram conteúdos geralmente trabalhados nos ensinos Médio e Fundamental. De acordo com os autores, nesse período do ENEM, em nenhuma questão analisada os conceitos de aceleração, força e carga elétrica foram utilizados.

$\mathrm{O}$ fato citado anteriormente mostra uma diferença de exames anteriores do ENEM em relação ao novo ENEM. Nas provas do novo exame, que estudamos, encontramos questões que envolvem aceleração e força; indicação que concorda também com Peixoto e Linhares (2010), que afirmam que, no novo ENEM, há a abordagem de mais conteúdos de Física do que no velho ENEM.

O trabalho de Peixoto, Martins e Linhares (2009) identifica questões do ENEM, nas edições dos anos de 2005, 2006, 2007 e 2008, que envolvem a disciplina de Física. Apresentam um resumo dos conteúdos abordados nestes exames, bem como sugestões de como inserir tais questões na escola como questões abertas. 
Pinheiro e Ostermann (2010) estudaram as duas provas do novo ENEM de 2009 (prova extraviada e prova oficialmente aplicada), focalizando na questão do grau de interdisciplinaridade nas provas de ciências da natureza e, também, na análise do grau de contextualização das questões do exame que envolveu Física. Os autores compararam, também, a prova do novo ENEM com provas de Física do vestibular tradicional da UFRGS(Universidade Federal do Rio Grande do Sul).

Pinheiro e Ostermann (2010) concluíram que os contextos privilegiados pelo ENEM em 2009 estão ligados a aplicações tecnológicas e a problemas ambientais e sociais; constataram, ainda, que, nas provas de 2009 , cerca de $90 \%$ das questões de ciências da natureza são contextualizadas. Esses pesquisadores também concluíram que a maioria das questões de ciências da natureza do novo ENEM/2009 não são interdisciplinares, apenas 25,5 \% das questões da prova de ciências da natureza são interdisciplinares, o que vai à direção do trabalho de Peixoto e Linhares (2010), que apontou uma redução das questões interdisciplinares na transição do velho para o novo ENEM. Uma hipótese nossa é que, a partir da edição do ENEM de 2010, ocorra um aumento do número de itens interdisciplinares, uma vez que, de acordo com a nota de aprovação da matriz para o Enem 2009 ,

Por recomendação da reunião, a partir da edição de 2010, os conhecimentos de Física, Química e Biologia, associados à matriz de referência de Ciências da Natureza e suas Tecnologias, devem expressar integração crescente entre as três áreas, adequando-se à perspectiva interdisciplinar das competências e habilidades adotadas na matriz de referência correspondente (BRASIL, 2009b, p. 1).

Essa nossa hipótese pode ser verificada por uma posterior pesquisa nas edições do novo ENEM a partir de 2010.

Peixoto e Linhares (2010) investigam a evolução do perfil do ENEM, na área de Ciências da Natureza, mais pontualmente em Física. Esses autores estudaram a prova do novo ENEM aplicada em 2009 e compararam com as edições anteriores do exame. Fizeram uma análise comparando o ENEM de 2009 com resultados gerados em pesquisa anterior realizada por Peixoto, Martins e Linhares (2009) que envolveu as provas do ENEM dos anos de 2005 a 2008. Segundo estes autores, as questões do novo ENEM/2009 continuam com uma característica forte de contextualização, enquanto que a abordagem interdisciplinar das questões foi reduzida no novo exame. Nas questões interdisciplinares do novo ENEM (2009), a integração da Física, Química e Biologia foi feita através de itens que exploram temas abrangentes como o meio ambiente. Segundo estes autores, 
nessa edição, foram encontradas dez questões na prova de ciências da natureza que integraram assuntos decorrentes das três disciplinas interligadas, através do tema Meio Ambiente.

Nossa pesquisa focaliza as cinco provas de Ciências da Natureza e suas Tecnologias do novo exame: a prova que vazou em 2009 (P09V), o caderno azul da prova oficialmente aplicada em 2009 (P09A), o caderno amarelo da primeira versão da prova aplicada em 2010 (P10A1), o caderno azul da segunda versão aplicada em 2010(P10A2) e, por fim, o caderno azul da prova aplicada em 2011 (P11A).

A área do conhecimento "Ciências da Natureza e suas Tecnologias" integra a Biologia, Química e Física, sendo que as questões da prova não estão separadas por disciplina escolar. Desse modo, selecionamos nas provas setenta e duas questões que abordam Física. As questões foram inicialmente classificadas por Competência e Habilidade segundo a Matriz de Referência do Exame (BRASIL, 2009a) para a área de Ciências da Natureza, que apresenta oito competências, cada uma abarcando um conjunto de habilidades, perfazendo trinta habilidades. As questões contemplam cinco Competências ( $\mathrm{C} 1, \mathrm{C} 2, \mathrm{C} 3, \mathrm{C} 5, \mathrm{C} 6)$, entre as Competências previstas na Matriz.

Em seguida, através da análise de conteúdo de Bardin (2010), propusemos um agrupamento das questões em categorias por Competência da mesma Matriz de Referência. Através da análise das categorias emergentes, procuramos avaliar a aproximação das questões selecionadas com as orientações dos Parâmetros Curriculares Nacionais para o Ensino Médio, PCN (BRASIL, 2000), das Orientações Complementares aos Parâmetros Curriculares Nacionais, PCN+ (BRASIL, 2002) e das Orientações Curriculares para o Ensino Médio, OCEM (BRASIL, 2006). A partir das categorias emergentes da análise, também procuramos fazer algumas orientações para o ensino de Física na perspectiva do novo ENEM.

Nosso trabalho se diferencia dos demais ao agrupar e estudar por competência os itens que evidenciam alguma Física. A seguir, apresentamos as definições de competência e habilidades, dadas segundo o documento básico do ENEM (BRASIL, 2002b):

Competências são as modalidades estruturais da inteligência, ou melhor, ações e operações que utilizamos para estabelecer relações com e entre objetos, situações, fenômenos e pessoas que desejamos conhecer. As habilidades decorrem das competências adquiridas e referem-se ao plano imediato do 'saber fazer'. Por meio das ações e operações, as habilidades aperfei- 
çoam-se e articulam-se, possibilitando nova reorganização das competências (BRASIL, 2002b, p. 11).

\section{Método}

As questões das Provas analisadas foram identificadas pelo número da questão no caderno de provas (Q30, Q83...) e pelo ano da Prova (P09, P10, P11), seguido do tipo de aplicação, conforme explicitado na introdução. Desse modo Q86P10A2, significa a questão 86 do caderno azul da segunda aplicação do Exame no ano de 2010.

Para cada uma das setenta e duas questões selecionadas, contendo Física, avaliamos a Competência e Habilidade $(\mathrm{C} / \mathrm{H})$ preferencialmente explorada, ainda que outras $\mathrm{C} / \mathrm{H}$ possam ter sido complementarmente requeridas. Essa metodologia exigiu refinamentos sucessivos, pois várias questões parecem, em uma primeira aproximação, explorar, sem privilégio, várias habilidades e somente o entendimento de uma habilidade $\mathrm{H}$ em uma determinada competência $\mathrm{C}$ possibilita uma escolha adequada de $\mathrm{C} / \mathrm{H}$.

Agrupamos posteriormente as questões por competência, procurando observar o que caracterizaria esse conjunto de questões. A metodologia adotada foi a análise de conteúdo de Bardin (2010), o que nos possibilitou categorizar as questões por competência. A análise de conteúdo, segundo Bardin (2010) é:

Um conjunto de técnicas de análise das comunicações visando obter por procedimentos sistemáticos e objetivos de descrição do conteúdo das mensagens, indicadores (quantitativos ou não) que permitam a inferência de conhecimentos relativos às condições de produção/recepção (variáveis inferidas) destas mensagens (BARDIN, 2010, p. 44).

A análise de conteúdo, segundo a autora, compõe-se das etapas: 1) préanálise; 2) exploração do material; 3) tratamento dos resultados, as inferências e interpretação. A pré-análise é a fase de organização do material, que pode utilizar vários procedimentos, tais como: leitura flutuante (estabelecer contato com os documentos: no nosso caso, a matriz de referência e demais dispositivos legais, além das provas de ciências da natureza do novo ENEM), formulação das hipóteses e dos objetivos, e elaboração de indicadores que fundamentem a interpretação final. Bardin (2010) destaca:

De fato, as hipóteses nem sempre são estabelecidas quando da pré-análise. Por outro lado, não é obrigatório ter-se como guia um corpus de hipóteses, 
para se proceder à análise. Algumas análises efetuam-se às "cegas” e sem ideias pré-concebidas (BARDIN, 2010, p. 124).

Na exploração do material os dados são codificados a partir das unidades de registro (UR) que "é a unidade de significação a codificar e corresponde ao seguimento de conteúdo a considerar como unidade de base, visando à categorização e à contagem frequencial."(BARDIN, 2010, p.130). Em nossa pesquisa, as unidades de registro são as situações-problema que abordam Física nas provas de Ciências da Natureza do ENEM. Para Bardin (2010),

A categorização é uma operação de classificação de elementos constitutivos de um conjunto, por diferenciação e, seguidamente, por reagrupamento segundo o gênero (analogia), com os critérios previamente definidos. As categorias são rubricas ou classes, as quais reúnem um grupo de elementos (unidades de registro, no caso da análise de conteúdo) sob um título genérico, agrupamento esse efetuado em razão das características comuns destes elementos (BARDIN, 2010, p. 145).

O critério de categorização pode ser sintático, léxico, expressivo ou semântico (categorias temáticas). Em nossa pesquisa, fizemos uma categorização semântica para as questões inseridas em cada competência. A categorização pode empregar dois processos inversos: pode-se fazer uma categorização com categorias a priori, sugeridas pelo referencial teórico, ou uma categorização com categorias $a$ posteriori, que emergem após a análise do material, como ocorreu no presente estudo. Na terceira etapa da análise de conteúdo, considera a autora que

Os resultados em bruto são tratados de maneira a serem significativos (falantes) e válidos. Operações estatísticas simples (percentagens), ou mais complexas (análise fatorial), permitem estabelecer quadros de resultados, diagramas, figuras e modelos, os quais condensam e põem em relevo as informações fornecidas pela análise. O analista, tendo à sua disposição resultados significativos e fiéis, pode então propor inferências e adiantar interpretações a propósito dos objetivos previstos, ou que digam respeito a outras descobertas inesperadas (BARDIN, 2010, p. 127).

As competências e as categorias são discutidas e exemplificadas a seguir. A distribuição das questões nas categorias estabelecidas é apresentada em quadros. 


\section{Categorização das questões}

\section{III.1 Categorização das questões inseridas na competência 1}

A competência de área 1, presente na matriz de referência do novo ENEM para área de ciências da natureza, é definida por: "Compreender as ciências naturais e as tecnologias a elas associadas como construções humanas, percebendo seus papéis nos processos de produção e no desenvolvimento econômico e social da humanidade."

Percebem-se oito questões nessa competência, separadas em três categorias, representando distintos contextos: a) cotidiano; b) tecnologia/novas tecnologias; c) avanço científico (QUADRO 1).

Quadro 1 - Questões nas categorias da competência 1.

\begin{tabular}{|c|c|c|}
\hline CATEGORIA & QUESTÕES & TOTAL \\
\hline Cotidiano & $\begin{array}{l}\text { Q58P10A2; Q67P10A2 } \\
\text { Q46P10A1; Q54P10A2 }\end{array}$ & 4 \\
\hline Tecnologia/novas tecnologias & $\begin{array}{c}\text { Q31P09A; Q80P10A1 } \\
\text { Q74P11A }\end{array}$ & 3 \\
\hline Avanço científico & Q5P09A & 1 \\
\hline
\end{tabular}

Fonte: Dados da pesquisa.

\section{a) Cotidiano}

A categoria cotidiano refere-se às questões que abordam situações relacionadas à vivência cotidiana das pessoas. A questão Q58P10A2 trabalha a existência das rádios piratas, destacando o problema cotidiano das pessoas da interferência das ondas ao escutarem as rádios; ela exige do estudante o conhecimento das grandezas que influenciam na sobreposição de sinais eletromagnéticos. A questão Q46P10A1 aborda a maneira corriqueira com que as pessoas lidam com o conceito de temperatura e calor, muitas vezes na contraposição aos respectivos modelos científicos. Nesse problema, o estudante precisa encontrar falhas nos modelos cotidianos de calor e temperatura. A questão Q54P10A2 aborda a falsa impressão cotidiana de que o espelho convexo de um veículo afasta a imagem dos objetos.

A categoria sugere um ensino de Física pautado na observação de fenômenos do cotidiano e a discussão da Física envolvida: discutir porque ocorrem interferências nas rádios, porque ocorre interferência quando se toca um celular 
perto de uma TV. Enfim, levantar situações do dia a dia de interesse discente. Com isso, incorpora-se a resolução de problemas na linha dessa categoria, além de preparar o estudante para uma melhor percepção e um bom entendimento de fenômenos corriqueiros. Essa categoria está em sintonia com os $\mathrm{PCN}+$ para o ensino de Física, pois o termo cotidiano se repete várias vezes no texto dos Parâmetros. Exemplo:

A Física deve apresentar-se, portanto, como um conjunto de competências especificas que permitam perceber e lidar com os fenômenos naturais e tecnológicos, presentes tanto no cotidiano mais imediato quanto na compreensão do universo distante, a partir de princípios, leis e modelos por ela construidos (BRASIL, 2002, p. 59).

\section{b) Tecnologia/novas tecnologias}

A categoria tecnologia/novas tecnologias abrange situações-problema sobre novos materiais com propriedades atípicas, como é o caso da Q80P10A1. Essa categoria admite questões que exploram os sistemas das tecnologias de transmissão de celular atualmente em uso no Brasil, como é o caso da Q31P09A.

A categoria sugere o trabalho com propriedades atípicas de materiais, ampliando a abordagem e exemplificação presente nos livros didáticos. Percebe-se, pela análise da questão Q80P10A1, que o conteúdo abordado nos livros didáticos sobre refração possui exceções. Essa questão sinaliza para o professor não ancorar sua fundamentação somente no livro didático. O professor deve estar atento às novas tecnologias existentes e às pesquisas/descobertas recentes na área de Física. Essa categoria também apresenta consonância com os $\mathrm{PCN}+$, ao esperar que o estudante esteja atento à ciência e tecnologia na atualidade, sendo capaz de

Acompanhar o desenvolvimento tecnológico contemporâneo, por exemplo, tomando contato com os avanços das novas tecnologias na medicina, através de tomografias ou diferentes formas de diagnóstico; na agricultura, através das novas formas de conservação de alimentos com o uso das radiações; ou ainda, na área de comunicações, com os microcomputadores, CDs, DVDs, telefonia celular, TV a cabo (BRASIL, 2002, p. 68).

As Orientações Curriculares para o Ensino Médio corroboram nossas observações, ao orientarem que

A tecnologia merece atenção especial, pois aparece nos Parâmetros Curriculares como parte integrante da área das Ciências da Natureza. Observase que, nos livros didáticos, os conteúdos disciplinares selecionados e tra- 
balhados pouco têm a ver com a tecnologia atual, ficando essa, na maioria das vezes, como simples ilustração. Deve-se tratar a tecnologia como atividade humana em seus aspectos prático e social, com vistas à solução de problemas concretos. Mas isso não significa desconsiderar a base científica envolvida no processo de compreensão e construção dos produtos tecnológicos (BRASIL, 2006, p. 46-47).

\section{c) Avanço científico}

A categoria avanço científico envolve questões relacionadas ao avanço de modelos científicos ao longo do tempo, admitindo situações-problema que abordam o conhecimento da evolução dos modelos do sistema planetário, como é o caso da Q5P09A.

Essa categoria sugere uma discussão da história da Física na educação básica, abordando a evolução das suas ideias, em especial as questões ligadas à Astronomia. É importante a compreensão de que o conhecimento não é algo pronto e acabado. Por essa categoria, percebe-se a relevância do contato discente com as origens e a evolução dos conceitos e das ideias presentes nos principais ramos da Física: o Eletromagnetismo, a Mecânica, a Termodinâmica, a Relatividade e a Física Quântica, conceitos que estão presentes também em outros ramos da Ciência. A categoria avanço científico está em sintonia com os $\mathrm{PCN}+$, que pressupõem para o final do Ensino Médio

Compreender a construção do conhecimento físico como um processo histórico, em estreita relação com as condições sociais, políticas e econômicas de uma determinada época.

Compreender, por exemplo, a transformação da visão de mundo geocêntrica para a heliocêntrica, relacionando-a às transformações sociais que the são contemporâneas, identificando as resistências, dificuldades e repercussões que acompanharam essa mudança (BRASIL, 2002, p. 67).

Também há ressonância com as OCEM ao afirmarem que:

O uso da história da ciência para enriquecer o ensino de Física e tornar mais interessante seu aprendizado, aproximando os aspectos cientificos dos acontecimentos históricos, possibilita a visão da ciência como uma construção humana (BRASIL, 2006, p. 64).

Por essa categorização, percebe-se uma maior concentração das questões relacionadas à explicação física de situações vivenciadas no cotidiano, com 50\% 
das questões dessa competência na categoria cotidiano. Tal fato reforça a relevância de um ensino de Física que aborde situações presentes no cotidiano discente.

\section{III.2 Categorização das questões inseridas na competência 2}

A competência de área 2 possui a seguinte redação: "Identificar a presença e aplicar as tecnologias associadas às ciências naturais em diferentes contextos."

Observam-se onze questões inseridas nessa competência, divididas em quatro categorias: a) funcionamento de aparelhos; b) projetos relacionados à segurança/economia/proteção; c) análise de circuitos elétricos mistos; d) previsão para o desempenho dos aparelhos depois de ligados (QUADRO 2).

Quadro 2 - Questões nas categorias da competência 2.

\begin{tabular}{|c|c|c|}
\hline CATEGORIA & QUESTÕES & TOTAL \\
\hline Funcionamento de aparelhos & $\begin{array}{c}\text { Q25P09V; Q17P09V } \\
\text { Q70P11A }\end{array}$ & 3 \\
\hline $\begin{array}{c}\text { Projetos relacionados à seguran- } \\
\text { ç/economia/proteção }\end{array}$ & $\begin{array}{c}\text { Q26P09V; Q47P10A1 } \\
\text { Q84P10A2; Q18P09A } \\
\text { Q19P09A }\end{array}$ & 5 \\
\hline Análise de circuitos elétricos mistos & Q45P09A & 1 \\
\hline $\begin{array}{c}\text { Previsão do desempenho de aparelhos, } \\
\text { depois de ligados }\end{array}$ & Q70P10A1; Q23P09V & 2 \\
\hline
\end{tabular}

Fonte: Dados da pesquisa.

As situações-problemas dessa competência foram agrupadas em categorias que tentam expressar os contextos aplicados às tecnologias associadas às ciências naturais, foco da competência.

\section{a) Funcionamento de aparelhos}

Envolve questões que exploram a compreensão do funcionamento de aparelhos presentes na contemporaneidade. Por exemplo: como funciona $o$ aparelho de ultrassonografia e como funciona o aparato que verifica possíveis adulterações em postos de combustíveis.

A categoria sugere ao docente trabalhar com a Física envolvida no funcionamento de aparelhos presentes no dia a dia. Pode-se estudar a Física teórica a partir da contextualização, mostrando o conceito físico aplicado na prática em aparelhos ou, o oposto, como na proposta da coleção do Grupo de Reelaboração do 
Ensino de Física (GREF), apresentando um aparelho e procurando discutir a Física envolvida no mesmo. Agindo dessa maneira, o professor atua em consonância com os PCN para o ensino de Física que coloca como importante o indivíduo: "Compreender a Física presente no mundo vivencial e nos equipamentos e procedimentos tecnológicos. Descobrir o "como funciona" de aparelhos" (BRASIL, 2000, p. 237).

\section{b) Projetos relacionados à segurança/economia/proteção}

Nessa categoria, estão as situações-problema que exploram uma análise relacionada com segurança na instalação elétrica de residências, carros e aparelhos elétricos. As questões, em sua maioria, exigem o cálculo da intensidade da corrente elétrica correta para execução de procedimentos de segurança em instalações elétricas. Por exemplo, a questão Q84P10A2 requer o cálculo da máxima corrente elétrica exigida por um chuveiro elétrico para a instalação adequada de um dispositivo de segurança (disjuntor). Também se inserem nessa categoria questões que exploram a escolha correta de dispositivos elétricos, visando a uma melhor eficiência/qualidade na instalação de aparelhos, como no caso da questão Q19P09A, em que o aluno avalia a potência correta de lâmpadas a serem instaladas nos cômodos de uma casa, visando à iluminação adequada.

Percebe-se, nessa categoria, uma tendência de questões práticas na área de eletricidade. Sendo assim, o novo ENEM sugere trabalhar a eletricidade de maneira contextualizada, procurando, por exemplo, mostrar aos estudantes a importância de dimensionamento correto da fiação de instalação de uma residência/construções. Nessa medida, sugere-se, também, direcionar as aulas para situações vivenciadas na prática. Verifica-se, também, a importância de trabalhar o cálculo de intensidade de correntes elétricas seguras para funcionamento de equipamentos, a partir de dados de potência e voltagem, podendo, então, explorar os dispositivos de segurança relacionados com a proteção do aumento da corrente, como fusíveis e disjuntores. Percebe-se, ainda, como essencial trabalhar curtocircuito, uma vez que dispositivos de segurança bem instalados evitam efeitos desastrosos de um curto-circuito. Por fim, percebe-se a necessidade da incorporação pelos alunos das relações entre potência, voltagem e corrente, assim como as relações entre voltagem, resistência e corrente. Essa categoria também está em consonância com os $\mathrm{PCN}+$ ao almejarem, para o final da escolaridade básica, o saber

Reconhecer a relação entre diferentes grandezas, ou relações de causaefeito, para ser capaz de estabelecer previsões. Assim, conhecer a relação 
entre potência, voltagem e corrente, para estimar a segurança do uso de equipamentos elétricos (BRASIL, 2002, p. 65).

\section{c) Análise de circuitos elétricos mistos}

Essa categoria engloba questões que abordam análise de circuito elétrico misto, como a questão Q45P09A, para a qual foi criado um falso contexto, desnecessário para a sua solução. Apesar do contexto hipotético para o circuito elétrico em foco, trata-se de uma questão clássica dos tradicionais livros de Ensino Médio. Sendo assim, a observação dessa questão indica que o ENEM pode explorar os tradicionais circuitos mistos com vários resistores em série e em paralelo. Entende-se que, para ser capaz de resolver a questão, basta ter resolvido problemas análogos.

\section{d) Previsão do desempenho de aparelhos, depois de ligados}

Refere-se às questões que trabalham com a previsão do que ocorre quando um aparelho elétrico é ligado fora de suas especificações técnicas ou com a previsão do desempenho de aparelhos, após a sua instalação.

A categoria sugere a relevância do ensino que explora os valores nominais gravados nos aparelhos. Cálculos da potência, corrente e consumo de energia de aparelhos ligados fora de suas especificações técnicas mostram-se frequentes no novo ENEM. É importante abordar como se processa o funcionamento dos aparelhos quando ligados fora de suas especificações técnicas. Nessa direção, os $\mathrm{PCN}+$ orientam que é importante:

- Em aparelhos e dispositivos elétricos residenciais, identificar seus diferentes usos e o significado das informações fornecidas pelos fabricantes sobre suas características (voltagem, frequência, potência etc.).

- Relacionar essas informações a propriedades e modelos físicos, visando explicar seu funcionamento e dimensionar circuitos simples para sua utilização.

- Compreender o significado das redes de $110 \mathrm{~V}$ e $220 \mathrm{~V}$, calibre de fios, disjuntores e fios-terra para analisar o funcionamento de instalações elétricas domiciliares e utilizar manuais de instrução de aparelhos elétricos, para conhecer procedimentos adequados a sua instalação, utilização segura ou precauções em seu uso (BRASIL, 2002, p. 76).

Em suma, ao analisar a categorização da Competência 2, infere-se a existência de uma concentração de questões na categoria projetos relacionados à 
segurança/economia/proteção, com abordagem relacionada com segurança/proteção na instalação elétrica de residências, carros e aparelhos elétricos.

\section{III.3 Categorização das questões inseridas na competência 3}

A competência 3 possui a seguinte redação: “Associar intervenções que resultam em degradação ou conservação ambiental a processos produtivos e sociais e a instrumentos ou ações científico-tecnológicos."

Observam-se, nessa competência, oito situações-problema agrupadas em quatro categorias: a) aproveitamento de lixo para produção de combustíveis visando à conservação ambiental; b) aproveitamento de energia a ser dissipada para maior produção de energia útil; c) intervenções que incentivam o uso de energia limpa; d) previsão de impactos ambientais e econômicos de intervenções humanas. (QUADRO 3)

Quadro 3 - Questões nas categorias da Competência 3.

\begin{tabular}{|c|c|c|}
\hline CATEGORIA & QUESTÕES & TOTAL \\
\hline $\begin{array}{c}\text { Aproveitamento de lixo para produção } \\
\text { de combustíveis visando à conservação } \\
\text { ambiental }\end{array}$ & $\begin{array}{c}\text { Q37P09V } \\
\text { Q10P09V }\end{array}$ & 2 \\
\hline $\begin{array}{c}\text { Aproveitamento de energia a ser } \\
\text { dissipada para maior produção de } \\
\text { energia útil }\end{array}$ & Q48P10A2 & 1 \\
\hline $\begin{array}{c}\text { Intervenções que incentivam o uso de } \\
\text { energia limpa }\end{array}$ & $\begin{array}{c}\text { Q87P10A1 } \\
\text { Q60P10A1 }\end{array}$ & 2 \\
\hline $\begin{array}{c}\text { Previsão de impactos ambientais e } \\
\text { econômicos de intervenções humanas }\end{array}$ & $\begin{array}{c}\text { Q57P10A1; Q8P09A } \\
\text { Q80P11A }\end{array}$ & 3 \\
\hline
\end{tabular}

Fonte: Dados da pesquisa.

\section{a) Aproveitamento de lixo para produção de combustíveis visando conserva- ção ambiental}

Essa categoria abrange questões que abordam o reaproveitamento de lixos (óleo, borra de café) para produção de biocombustíveis. 


\section{b) Aproveitamento de energia a ser dissipada para maior produção de energia}

útil

Essa categoria aborda questões que realizam intervenções que permitem o aproveitamento de energia que seria dissipada para geração de mais energia útil, melhorando a eficiência de todo o processo de obtenção de energia útil.

\section{c) Intervenções que incentivam o uso de energia limpa}

Abrange questões que exploram o conhecimento sobre formas limpas de obtenção de energia elétrica, como é o caso das usinas geotérmicas e fotovoltaicas.

\section{d) Previsão de impactos ambientais e econômicos de intervenções humanas}

Abrange questões que exigem a análise dos impactos ambientais de determinadas intervenções humanas, como, por exemplo, a instalação de usinas hidrelétricas ou a industrialização de cidades.

As categorias emergentes retratam a competência em foco, pois expressam o tipo de análise que o estudante deve saber fazer, ao concluir a educação básica na perspectiva expressa pela competência 3. A categoria aproveitamento de lixo para produção de combustíveis visando à conservação ambiental mostra a importância do trabalho com a reciclagem, possibilitando, além de apresentar as teorias da Física, discutir ações que possam melhorar a qualidade do ambiente. Além disso, permite abordar a possibilidade de reaproveitamento de determinados tipos de lixo para a produção de energia útil, conscientizando sobre a responsabilidade de cada um para com o meio ambiente e as consequências de nossas atitudes. É interessante discutir os aspectos negativos de determinadas ações, apresentando possíveis catástrofes que acontecem quando não se cuida do ambiente. É importante desenvolver no aluno o apreço e a consciência cidadã para com o outro e com a natureza, ao compreender as consequências das ações realizadas sobre o planeta, com seus recursos naturais limitados.

A categoria aproveitamento de energia a ser dissipada para maior produção de energia útil sinaliza uma preocupação com a melhoria da eficiência de processos de produção de energia útil, evitando-se, assim, o desperdício de energia e prolongando nossas reservas de recursos energéticos não renováveis. Nessa linha, pode-se apresentar processos de geração de energia útil e discutir com os alunos as alternativas para o aumento da eficiência do processo. A questão Q48P10A2 mostra que os alunos devem ter contato com métodos de aumento da eficiência energética como, por exemplo, a cogeração que proporciona a redução de emissão de gases de efeito estufa, contribuindo para isso o aumento da eficiência energética 
do processo, implicando menor gasto energético para mais energia produzida e, por conseguinte, menor impacto ambiental.

As categorias "intervenções que incentivam o uso de energia limpa" e "previsão de impactos ambientais e econômicos de intervenções humanas" sinalizam a relevância de se trabalhar com os estudantes possíveis formas de usinas geradoras de energia elétrica, discutindo principalmente as vantagens e desvantagens de cada tipo de usina tanto do ponto de vista econômico, quanto do ponto de vista ambiental, considerando a abordagem da Física envolvida em cada sistema. $\mathrm{O}$ novo ENEM nos mostra que é insuficiente a abordagem do capítulo de energia em muitos livros didáticos, pois, além dos tipos de energia e seus cálculos, deve-se abordar as várias possibilidades de geração de energia útil. Mostra-se essencial incorporar as discussões sobre impactos ambientais, além das possíveis formas de usinas geradoras de eletricidade. As categorias da competência 3 estão em harmonia com as competências em Física citadas nos $\mathrm{PCN}+$, pois o concluinte da educação básica deve ser capaz de

Promover situações que contribuam para a melhoria das condições de vida da cidade onde vive ou da preservação responsável do ambiente, conhecendo estruturas de abastecimento de água e eletricidade de sua comunidade e dos problemas delas decorrentes, sabendo posicionar-se, argumentar e emitir juizos de valor (BRASIL, 2002, p. 68).

\section{III.4 Categorização das questões inseridas na competência 5}

A competência 5 apresenta a seguinte redação: "Entender métodos e procedimentos próprios das ciências naturais e aplicá-los em diferentes contextos."

Agrupamos as doze questões que pertencem a essa competência em duas categorias, representando os contextos: a) cotidiano e b) científico (QUADRO 4).

Quadro 4 - Questões nas categorias da competência 5.

\begin{tabular}{|c|c|c|}
\hline CATEGORIA & QUESTÕES & TOTAL \\
\hline \multirow{3}{*}{ Cotidiano } & $\begin{array}{l}\text { Q24P09A; Q72P10A1 } \\
\text { Q64P10A2; Q78P11A }\end{array}$ & 5 \\
\hline \multirow{3}{*}{ Científico } & Q84P11A & \\
& Q18P09V; Q31P09V & 7 \\
& Q40P09V; Q29P09A & \\
\hline
\end{tabular}

Fonte: Dados da pesquisa. 
Essas duas categorias estão relacionadas com contextos em que se inserem os procedimentos das ciências naturais, ora relacionado com situações vivenciadas no cotidiano dos estudantes e ora relacionado aos temas científicos.

A categoria cotidiano aborda situações presentes no cotidiano dos alunos, reforçando a relevância de incorporar nas aulas de Física, por exemplo, a leitura e interpretação de medidores de variados tipos: relógio de luz, relógio de água, dentre outros. Percebe-se, nessa categoria, a sintonia com uma das competências apontadas pelo $\mathrm{PCN}+$ como desejável para o estudante ao término da escolaridade básica: ser capaz de "ler um medidor de água ou de energia elétrica" (BRASIL, 2002, p. 63).

Observa-se no novo ENEM uma opção pelo cotidiano, categoria emergente em várias competências, em acordo com a proposta de um novo Ensino Médio, que busca a aquisição de competências gerais. Segundo as OCEM

Para se conduzir um ensino de forma compativel com uma promoção das competências gerais, é importante tomar como ponto de partida situações mais próximas da realidade do aluno. O primeiro passo de um aprendizado contextualizado pode vir da escolha de fenomenos, objetos e coisas do universo vivencial. Problemas do mundo real tendem a propiciar, frequentemente, soluções mais criativas e são presumivelmente mais significativos e motivadores que problemas artificiais. É interessante, para os alunos, poderem trazer o mundo abstrato da Física para o mundo construído diariamente em suas experiências (BRASIL, 2006, p. 61).

A categoria cientifico incorpora questões distantes do convívio cotidiano, como, por exemplo, situações-problema relacionadas com decaimento radioativo, análise de gráficos de dilatação irregular da água, energia potencial elástica, etc. Tais situações encontram-se próximas de contextos específicos. Essa categoria indica a relevância do trabalho com situações/conceitos não corriqueiros, ampliando o universo temático e conceitual dos alunos.

\section{III.5 Categorização das questões inseridas na competência 6}

A competência 6 possui a seguinte redação: "Apropriar-se de conhecimentos da Física para, em situações-problema, interpretar, avaliar ou planejar intervenções científico-tecnológicas."

As trinta e três questões dessa competência foram agrupadas em cinco categorias: a) interpretação de experimentos; b) projeção/previsão, com o auxilio de cálculos; c) funcionamento de aparelhos/aparatos tecnológicos; d) explicação de 
fenômenos naturais; e) previsões, com redução de impactos ambientais/economia de energia (QUADRO 5).

Quadro 5-Questões nas categorias da competência 6.

\begin{tabular}{|c|c|c|c|}
\hline CATEGORIAS & \multicolumn{2}{|c|}{ QUESTÕES } & TOTAL \\
\hline $\begin{array}{l}\text { interpretação de } \\
\text { experimentos }\end{array}$ & $\begin{array}{l}\text { Q65P10A2 } \\
\text { Q58P10A1 } \\
\text { Q75P10A1 }\end{array}$ & $\begin{array}{l}\text { Q73P11A } \\
\text { Q77P11A }\end{array}$ & 5 \\
\hline $\begin{array}{l}\text { projeção/previsão, com o } \\
\text { auxílio de cálculos }\end{array}$ & $\begin{array}{l}\text { Q17P09A } \\
\text { Q45P09V } \\
\text { Q30P09A } \\
\text { Q35P09A }\end{array}$ & $\begin{array}{l}\text { Q38P09A } \\
\text { Q44P09V } \\
\text { Q60-P11 }\end{array}$ & 7 \\
\hline $\begin{array}{l}\text { funcionamento de } \\
\text { aparelhos/aparatos } \\
\text { tecnológicos }\end{array}$ & $\begin{array}{l}\text { Q90P10A2 } \\
\text { Q28P09V } \\
\text { Q39P09A } \\
\text { Q57P10A2 } \\
\text { Q70P10A2 } \\
\text { Q81P10A2 }\end{array}$ & $\begin{array}{l}\text { Q85P10A2 } \\
\text { Q32P09A } \\
\text { Q52P10A1 } \\
\text { Q46P11A } \\
\text { Q56P11A } \\
\text { Q66P11A }\end{array}$ & 12 \\
\hline $\begin{array}{c}\text { explicação de fenômenos } \\
\text { naturais }\end{array}$ & $\begin{array}{l}\text { Q53P10A1 } \\
\text { Q49P10A2 }\end{array}$ & $\begin{array}{l}\text { Q48P10A1 } \\
\text { Q1P09V }\end{array}$ & 4 \\
\hline $\begin{array}{l}\text { previsão, com redução de } \\
\text { impactos ambientais/ } \\
\text { economia de energia }\end{array}$ & $\begin{array}{l}\text { Q35P09V } \\
\text { Q14P09A } \\
\text { Q19P09V }\end{array}$ & $\begin{array}{l}\text { Q33P09V } \\
\text { Q20P09A }\end{array}$ & 5 \\
\hline
\end{tabular}

Fonte: Dados da pesquisa.

\section{a) Interpretação de experimentos}

Nessa categoria, colocamos as questões que exigem a capacidade de fazer interpretações/explicações relacionadas a demonstrações experimentais/brinquedos. A questão Q65P10A2 exige explicar fisicamente o porquê do movimento de descida do frasco do Ludião. O Ludião é uma demonstração experimental que aparece em alguns livros didáticos e pode ser levado para a sala de aula como um recurso didático em aulas de hidrostática.

Essa categoria é interessante porque relembra ao professor a relevância das atividades experimentais para complementação do processo de ensinoaprendizagem. É importante explorar a parte de atividades experimentais dos livros didáticos. Mesmo que a escola não possua um laboratório de Física é relevante 
incentivar os estudantes a realizarem experiências, mesmo que sejam aquelas de baixo custo presentes em muitos livros. Verifica-se que as experiências retratadas no ENEM não exigem materiais de custo elevado para serem elaboradas. Essa categoria sinaliza a importância de saber lidar com experimentos simples, pois até o momento, o exame não exigiu explicação alguma de experimentação sofisticada.

Verifica-se, nessa categoria, a sintonia com os PCN+:

$E$ indispensável que a experimentação esteja sempre presente ao longo de todo o processo de desenvolvimento das competências em Física, privilegiando-se o fazer, manusear, operar, agir, em diferentes formas e níveis. $E$ dessa forma que se pode garantir a construção do conhecimento pelo próprio aluno, desenvolvendo sua curiosidade e o hábito de sempre indagar, evitando a aquisição do conhecimento cientifico como uma verdade estabelecida e inquestionável.

Isso inclui retomar o papel da experimentação, atribuindo-lhe uma maior abrangência, para além das situações convencionais de experimentação em laboratório. As abordagens mais tradicionais precisariam, portanto, ser revistas, evitando "experiências" que se reduzem à execução de uma lista de procedimentos previamente fixados, cujo sentido nem sempre fica claro para o aluno. É tão possível trabalhar com materiais de baixo custo, tais como pedaços de fio, pequenas lâmpadas e pilhas, quanto com kits mais sofisticados, que incluem multímetros ou osciloscópios. A questão a ser preservada, menos do que os materiais disponiveis, é, novamente, que competências estarão sendo promovidas com as atividades desenvolvidas.

Experimentar pode significar observar situações e fenômenos a seu alcance, em casa, na rua ou na escola, desmontar objetos tecnológicos, tais como chuveiros, liquidificadores, construir aparelhos e outros objetos simples, como projetores ou dispositivos óptico-mecânicos. Pode também envolver desafios, estimando, quantificando ou buscando soluções para problemas reais (BRASIL, 2002, p. 84).

Os PCN colocam como competência almejável no indivíduo dentro do campo da investigação e compreensão o saber: "Interpretar e criticar resultados a partir de experimentos e demonstrações" (BRASIL, 2000, p. 216).

\section{b) Projeção/previsão, com o auxilio de cálculos}

Essa categoria surgiu ao observarmos questões que exigem o uso da Física para fazer avaliações/planejamentos/previsões, através de cálculos. Na questão Q17P09A, deve-se avaliar, usando a fórmula de aceleração centrípeta, o valor ideal 
para o raio da curva de uma ferrovia, para que os passageiros não sofram desconfortos. A questão Q35P09A requer o cálculo da área ideal para o projeto de um dispositivo para captar energia solar; são questões que exigem um planejamento de cálculo.

Essa categoria reforça a importância do cálculo em Física, utilizado na medida correta. A questão Q44P09V apresenta no enunciado uma fórmula a ser usada na avaliação da velocidade de uma chuva. Trata-se da fórmula do efeito Doppler deduzida para o cálculo de velocidades de objetos, através da incidência de micro-ondas. Essa equação é pouco apresentada nos livros de Ensino Médio, que usualmente lidam com o efeito Doppler para ondas mecânicas de som. É importante trabalhar no Ensino Médio a manipulação adequada das fórmulas com a correta transformação de unidades, incorporando a análise dimensional e as devidas transformações de unidades para atribuição de valores nas fórmulas. $\mathrm{Na}$ questão Q44P09V, percebe-se a relevância da exploração de fórmulas distintas daquelas presentes nos livros do Ensino Médio, ampliando a ideia de modelos em Física. Sobre as fórmulas e os cálculos em Física, as OCEM mencionam:

A Física também deve ser entendida como cultura, na medida em que a escola tem o dever de assegurar o acesso da população a uma parcela dos saberes produzidos. Não se trata, todavia, de abandonar os conteúdos ou partir para generalidades; os conteúdos devem ser explorados com rigor, mas devem passar por escolhas criteriosas e tratamento didático adequado, a fim de que não se resumam a amontoados de fórmulas e informações desarticuladas. Só a história não é suficiente, pois é necessário ir além do processo e compreendê-lo, para garantir a investigação. Longe de noções vazias e sem sentido, necessita-se ensinar "como as coisas funcionam”. É nessa perspectiva que entram os conteúdos específicos, inclusive o necessário uso dos cálculos (BRASIL, 2006, p. 54).

Os cálculos em Física são importantes e as fórmulas são necessárias, mas precisam estar articuladas para lhes garantir significado. Percebem-se, também, nessa categoria, questões que usam a Física para cálculos financeiros, para avaliar lucros indevidos ou o custo financeiro de equipamentos elétricos ligados durante certo período. Na questão Q38P09A, deve-se avaliar, com o uso da fórmula de dilatação, o ganho financeiro do dono de um posto, ao efetuar o aquecimento ilícito de seu combustível. A questão Q45P09V pergunta qual o acréscimo em reais em uma conta de luz se um grupo de garotas passasse a utilizar um secador de cabelos por determinado período. Isso reforça a relevância de explorar situações cotidianas que envolvam Física e dinheiro: pedir aos alunos que interpretem suas 
contas de luz, propor problemas relacionados à conta de luz ou até mesmo de água. $\mathrm{Na}$ conta de água, pode se explorar o conceito físico da vazão, além do custo do litro de água, etc. O custo pode ser um motivador para o aprendizado de Física, assim como o é para a Matemática.

\section{c) Funcionamento de aparelhos/aparatos tecnológicos}

Essa categoria emergiu ao observarmos questões envolvendo avaliar/ interpretar situações ligadas ao funcionamento de aparelhos/equipamentos/ aparatos tecnológicos do cotidiano de grande parte das pessoas. Tais problemas exigem o conhecimento da Física do funcionamento dos aparelhos. Também se enquadram nessa categoria as questões que exigem do solucionador a comparação de eficiência de aparelhos ou comparação da diferença de tipos de ondas emitidas por equipamentos/aparelhos.

A Q39P09A explora o funcionamento de uma geladeira e necessita que se saiba que, no refrigerador, o calor flui de forma não espontânea de dentro para fora do mesmo. A questão Q81P10A2 requer o entendimento do princípio físico básico de funcionamento de um dínamo de bicicleta. A questão Q90P10A2 aborda o entendimento de um tipo de densímetro, presente nos postos de combustíveis, com o objetivo de dificultar as adulterações de combustíveis. A situação-problema Q70P10A2 explora o funcionamento de bobinas usadas na indução de correntes elétricas no tecido cerebral.

Esse grupo de questões sinaliza a importância da Física das coisas, neste caso a Física dos aparelhos, principalmente os presentes no cotidiano. Podem-se observar equipamentos cotidianos e procurar discutir a Física neles envolvida: Como funciona um dínamo? Como funciona o alternador de um automóvel? Como funciona um densímetro? Como funciona o calibrador de pneus de um posto de gasolina? Qual a Física dos novos monitores/telas de computador/TV? Como funciona um relógio de luz? Qual a Física das telas sensíveis ao toque dos celulares e TV inteligentes? Qual a função de um prato giratório dentro do aparelho de micro-ondas? Como funciona o GPS? A palavra "funcionamento" é recorrente nos $\mathrm{PCN}+$, que alertam:

[...] menos ênfase deve ser dada, por exemplo, às escalas termométricas, e mais atenção aos aspectos propriamente termodinâmicos, envolvendo o funcionamento de máquinas térmicas, o próprio conceito de calor e modelos explicativos sobre seu trânsito na matéria, seja no nível macroscópico ou microscópico (BRASIL, 2002, p. 73). 
Os PCN+ consideram que, para adquirir determinadas competências, é importante ao estudante:

[...] reconhecer a relação entre fenômenos magnéticos e elétricos para explicar o funcionamento de motores elétricos e seus componentes, interações envolvendo bobinas e transformações de energia. [...] compreender o funcionamento de diferentes geradores, para explicar a produção de energia em hidrelétricas, termelétricas etc. Utilizar esses elementos na discussão dos problemas associados desde a transmissão de energia até sua utilização residencial. [...] compreender o funcionamento de circuitos oscilantes e o papel das antenas, para explicar a modulação, emissão e recepção de ondas portadoras, como no radar, rádio, televisão ou telefonia celular (BRASIL, 2002, p. 76-77).

\section{d) Explicação de fenômenos naturais}

Essa categoria surgiu ao observarmos questões que exigem o uso de conceitos da Física para interpretar/explicar fenômenos naturais. A Q33P10A1 exige interpretar o motivo do sumiço de uma das listas mais proeminentes do planeta Júpiter. A situação-problema Q48P10A1 requer a explicação sobre a transmissão natural de ondas de rádio, através da ionosfera terrestre entre o litoral do Brasil e a região amazônica. A situação-problema Q49P10A2 exige avaliar o motivo físico da mudança de posição da sombra de uma árvore ao longo do dia. O item Q1P09V aborda o conhecimento de uma etapa do ciclo da água.

Percebe-se, nessa categoria, proximidade com orientações dos PCN que ressaltam a importância de dar ao ensino de Física novas dimensões. Os PCN sugerem: “[...] promover um conhecimento contextualizado e integrado à vida de cada jovem. Apresentar uma Física que explique a queda dos corpos, o movimento da lua ou das estrelas no céu, o arco-íris [...]” (BRASIL, 2000, p. 230).

\section{e) Previsão, com redução de impactos ambientais/economia de energia}

Nessa categoria se enquadram as questões que exigem análises que proporcionam a redução de impactos no meio ambiente ou o conhecimento de possíveis impactos ambientais. Na questão Q35P09V, deve-se escolher o material adequado em termos de calor específico e capacidade térmica para a construção de uma quadra com o intuito de possibilitar um melhor conforto térmico a posteriori. Ou seja, devem-se escolher materiais de maneira adequada para evitar danos à natureza local, como, por exemplo, o surgimento de ilhas de calor. 
Na questão Q33P09V, o estudante tem que escolher dentre sistemas conversores de energia, apresentados em uma tabela, aquele que mais se beneficiaria de investimentos em pesquisa para ter sua eficiência aumentada, supondo não haver determinadas limitações impostas por leis Físicas. Ou seja, para responder à questão, o aluno deve considerar o investimento em energia solar como mais interessante, sobretudo por ser uma forma de energia não poluente. Encontram-se também nessa categoria as questões que requerem avaliar ações/medidas que resultem em economia de energia, pois, ao economizar energia, temos redução de impactos negativos no meio ambiente. Na questão Q20P09A, o estudante deve escolher qual ação resulta em uma economia de energia em uma estação geradora de eletricidade abastecida por combustível fóssil.

Essa categoria sinaliza a importância de trabalhar situações-problema que abordem análise de impactos ambientais proporcionados por determinadas escolhas. Os processos de geração de energia útil podem ser apresentados, incorporando principalmente os impactos ambientais oriundos de cada processo. Com isso, o aluno vai adquirir competências para avaliar a melhor escolha. Ao ensinar capacidade térmica e calor específico, é adequado mostrar a importância desse conceito para avaliar o melhor material para projetos de construções variadas. É benéfico discutir a Física, considerando também os malefícios de certas escolhas. Essa categoria possui harmonia com os $\mathrm{PCN}+$, que sinalizam a importância do estudante saber

identificar os diferentes sistemas de produção de energia elétrica, os processos de transformação envolvidos e seus respectivos impactos ambientais, visando escolhas ou análises de balanços energéticos (BRASIL, 2002, p. 74).

Também, nessa categoria, há ressonância com as orientações curriculares para o Ensino Médio que comentam que

Uma formação crítica exige por parte dos sujeitos a capacidade de discutir abertamente questões resolvidas em instâncias tecnocráticas, que devem estar amparadas em sólida formação científica e tecnológica. Implica que seja possível discriminar o domínio da ciência e da tecnologia do debate ético e político. O critério utilizado para a compra de uma geladeira contém aspectos técnicos e pode ser auxiliado por conhecimentos científicos. Mas quando se solicita a posição do cidadão sobre clonagem, pesticidas agrícolas ou uso de energia nuclear, entra também o debate ético e político, na medida em que esse uso compromete a própria existência humana. Mesmo 
quando se defende a clonagem terapêutica ou o uso pacífico da energia nuclear, devem ser discutidos os perigos potencialmente envolvidos nisso, já que a história deixou ensinamentos tão dolorosos quanto os escombros de Hiroshima. A formação por competências deve ter por objetivo possibilitar ao sujeito opinar nessas esferas (BRASIL, 2006, p. 47).

\section{Considerações finais}

De modo geral, percebe-se que muitas orientações explicitadas, a partir das categorias emergentes, concordam com as orientações dos PCN, pois o novo ENEM se aproxima da proposta dos PCN e PCN+. Ainda assim, percebem-se questões tradicionais de Física, apresentadas em "contextos" desnecessários para a sua solução. Por exemplo, uma questão que explorou a análise de um circuito elétrico misto de vários resistores associados dentro de um contexto hipotético, que, se for subtraído do item, não impede sua resolução. Apesar de vários itens no novo ENEM se aproximarem da perspectiva de um ensino de Física como sugerido nos PCN, verificam-se reminiscências de uma abordagem tradicional de Física no exame, de provas de vestibulares. Esse fato pode ser um reflexo da visão e formação conservadora de elaboradores de itens do novo exame, o que poderá ser minimizado com a ampliação e o aprimoramento do banco de questões da Prova.

Percebe-se da análise das questões agrupadas por competência que o novo ENEM focaliza coisas e situações do cotidiano das pessoas. Trata-se de uma sinalização para a exploração da "Física das coisas" que nos cercam, contribuindo para a formação de um cidadão que melhor compreende o mundo que o cerca. É, ainda, importante compreender a essência de um ensino por competência. A partir das competências e habilidades que se deseja desenvolver nos educandos, escolhem-se situações que demandam conteúdos e objetos de conhecimento de Física. Tal abordagem preconizada pelos resultados da Pesquisa em Ensino e pela Legislação Educacional; configura-se como uma mudança de paradigma no ensino de Física, contrapondo-se ao currículo fragmentado e "conteudista", ainda fortemente percebido tanto na formação quanto em sua reprodução na práxis docente.

O ensino de Física pautado em competências e habilidades a serem desenvolvidas nos estudantes, proposto no novo ENEM, ao pretender ser a principal porta de entrada para o Ensino Superior no país, pode se tornar, com o seu aprimoramento, um indutor da qualidade do ensino. 


\section{Referências}

BARDIN, Laurence. Análise de conteúdo. 5. ed. Lisboa: Edições 70 Ltda., 2010.

BRASIL. Ministério da Educação. Secretaria de Ensino Médio e Tecnológico. Orientações curriculares para o ensino médio: ciências da natureza, matemática e suas tecnologias. Brasília: MEC/SEMTEC, 2006.

BRASIL. Ministério da Educação. Secretaria de Ensino Médio e Tecnológico. PCN+ ensino médio: orientações educacionais complementares aos Parâmetros Curriculares Nacionais. Ciências da Natureza, Matemática e suas Tecnologias. Brasília: MEC/SEMTEC, 2002a.

BRASIL. Instituto Nacional de Estudos e Pesquisas Educacionais Anísio Teixeira. Matriz de referência para o Enem 2009. Brasília: MEC/INEP, 2009a.

BRASIL. Ministério da Educação. Parâmetros Curriculares Nacionais para o Ensino Médio. Ciências da natureza, matemática e suas tecnologias. Brasília: MEC/SEMTEC, 2000.

BRASIL. Lei no 9.394, de 20 de dezembro de 1996. Dispõe sobre as Diretrizes e Bases da Educação Nacional. Diário Oficial da União, Brasília, 23 dez.1996.

BRASIL. Ministério da Educação. Exame nacional do ensino médio- documento básico. Brasília, 2002b. Disponível em:

$<$ http://www.publicacoes.inep.gov.br/arquivos/\%7BE57A3D8A-B535-470EAD0C-1089028BA212\%7D_documento_basico_enem_2002_353.pdf >. Acesso em: 20 fev. 2013.

BRASIL. Ministério da Educação. Nota de aprovação da matriz de referência do ENEM 2009. 2009b. Representação da Andifes no Comitê de Governança. Instituto Nacional de Estudos e Pesquisas Educacionais. Associação Nacional dos Dirigentes das Instituições Federais de Ensino Superior. Disponível em: $<$ http://portal.mec.gov.br/dmdocuments/matriz_referencia_novoenem.pdf $>$. Acesso em: 19 out. 2012.

PEIXOTO, K. C. Q. da C.; LINHARES, M. P. Novo Enem: o que mudou? Uma investigação dos conceitos de Física abordados no exame. In: ENCONTRO DE PESQUISA EM ENSINO DE FÍSICA, 12, 2010, Águas de Lindóia. Anais... Águas de Lindóia: Sociedade Brasileira de Física, 2010. Disponível em: 
$<$ http://www.sbf1.sbfisica.org.br/eventos/epef/xii/sys/resumos/T0058-1.pdf $>$. Acesso em: 27 set. 2012.

PEIXOTO, K. C. Q. da C.; MARTINS, R. L. C.; LINHARES, M. P.. Um olhar investigativo sobre as questões do Enem que abordam a Física. In: SIMPÓSIO NACIONAL DE ENSINO DE FÍSICA, 18, 2009, Vitoria. Anais... São Paulo: Sociedade Brasileira de Física, 2009. Disponível em:

$<$ http://www.sbf1.sbfisica.org.br/eventos/snef/xviii/sys/resumos/T0436-1.pdf $>$. Acesso em: 03 out. 2012.

PINHEIRO, N. C.; OSTERMANN, F. Uma análise comparativa das questões de física no novo ENEM e em provas de vestibular no que se refere aos conceitos de interdisciplinaridade e de contextualização. In: ENCONTRO DE PESQUISA EM ENSINO DE FÍSICA, 12, 2010, Águas de Lindóia. Anais... São Paulo: Sociedade Brasileira de Física, 2010. Disponível em:

$<$ http://www.sbf1.sbfisica.org.br/eventos/epef/xii/sys/resumos/T0196-1.pdf $>$.

Acesso em: 01 out. 2012.

SILVA, A. M. M.; PRESTES, R. F. Conhecimentos de Física nas questões do Exame Nacional do Ensino Médio. In: SIMPÓSIO NACIONAL DE ENSINO DE FÍSICA, 18, 2009, Vitória-ES. Anais... São Paulo: Sociedade Brasileira de Física, 2009. Disponível em:

$<$ http://www.sbf1.sbfisica.org.br/eventos/snef/xviii/sys/resumos/T0419-1.pdf $>$. Acesso em: 03 out. 2012. 